Check for updates

Cite this: RSC Adv., 2018, 8, 40387

Received 2nd October 2018

Accepted 15th November 2018

DOI: $10.1039 / c 8 r a 08161 a$

rsc.li/rsc-advances

\section{Investigation of the metabolic stability of olmutinib by validated LC-MS/MS: quantification in human plasma}

\begin{abstract}
Mohamed W. Attwa, (D) a Adnan A. Kadi, ${ }^{a}$ Hany W. Darwish ${ }^{\star a b}$ and Ali S. Abdelhameed ${ }^{a}$
Olmutinib (OTB, OlitaTM) is an orally available third-generation epidermal growth factor receptor tyrosine kinase inhibitor (EGFR TKI). It was developed by Boehringer Ingelheim and Hanmi Pharmaceutical Co. Ltd for the cure of non-small cell lung cancer (NSCLC). In May 2016, OTB was approved in South Korea for the treatment of patients suffering from metastatic or locally advanced EGFR T790M mutation-positive NSCLC. A LC-MS/MS methodology was validated for OTB quantification in human plasma. An extended application for this validated LC-MS/MS is OTB metabolic stability evaluation. Chromatographic separation of OTB and ponatinib (PNT, IS) was attained using a reversed phase with isocratic elution. The linearity of the developed LC-MS/MS method ranged from 5.00 to $500.00 \mathrm{ng} \mathrm{mL}^{-1}$ with $r^{2} \geq 0.9999$ in human plasma. LOD and LOQ were 1.12 and $3.39 \mathrm{ng} \mathrm{mL}^{-1}$, respectively. The intra-day and inter-day precision and accuracy were 1.17 to $2.75 \%$ and 97.86 to $101.48 \%$, respectively. The intrinsic clearance

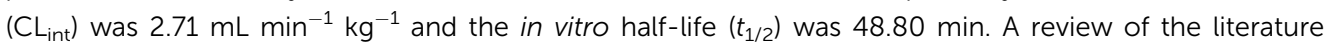
revealed that there are no previous articles about the quantification of OTB in human plasma using LCMS/MS or its metabolic stability assessment.
\end{abstract}

\section{Introduction}

Cancer is considered as one of the major reasons of death, and it causes more than one fourth of the world's deaths. ${ }^{\mathbf{1}}$ Molecular targeting strategies have lately been utilized for curing disseminated cancer. $^{2}$ From all types of cancers reported worldwide, lung cancer is the major reason of death because it was responsible for around $20 \%$ of cancer deaths (1.59 million deaths) in $2012 .^{3}$ Non-small cell lung cancers (NSCLCs) represent almost $90 \%$ of lung cancers. ${ }^{4,5}$ Patients suffering from advanced-stage NSCLCs accompanied by active mutations of epidermal growth factor receptors (EGFR) have received a firstline targeted medication of tyrosine kinase inhibitors (TKIs). ${ }^{6}$ The first-generation TKIs such as gefitinib and erlotinib have a very good initial response against these active mutations of EGFR. ${ }^{7}$ However, a major drawback for this group appears during the first year of treatment, which is the acquired resistance development in most patients. ${ }^{7,8}$ This has led to vigorous attempts by scientists to develop the second generation of EGFR TKIs (e.g., avitinib, dacomitinib, etc.), which is irreversibly linked to a domain in EGFR called TK. ${ }^{\mathbf{8 9}}$ The third-generation

\footnotetext{
${ }^{a}$ Department of Pharmaceutical Chemistry, College of Pharmacy, King Saud University, P. O. Box 2457, Riyadh, 11451, Kingdom of Saudi Arabia.E-mail: hdarwish@ksu.edu. sa; mzeidan@ksu.edu.sa; akadi@ksu.edu.sa; asaber@ksu.edu.sa; Fax:+966114676 220; Tel: +966114677343

${ }^{b}$ Analytical Chemistry Department, Faculty of Pharmacy, Cairo University, Kasr El-Aini St., Cairo 11562, Egypt
}

TKIs exhibit the advantages of the second-generation drugs by hindering mutations of EGFR and conquering T790M resistance mutation with very reasonable selectivity for these mutations over other wild-type EGFR. ${ }^{8,9}$

OTB (HM61713, Fig. 1) is an orally available EGFR TKI. Its IUPAC name is $N-\{3-[(2-\{[4-(4-m e t h y l-1-p i p e r a z i n y l) p h e n y l]$ amino\}thieno[3,2-d]pyrimidin-4-yl)oxy] phenyl $\}$ acrylamide. The FDA granted a breakthrough therapy designation for OTB in NSCLC. ${ }^{10}$ In May 2016, OTB was approved in South Korea under the trade name Olita ${ }^{\mathrm{TM}}$ for management of patients suffering from metastatic or local advanced EGFR T790M mutation-positive NSCLC. ${ }^{\mathbf{1 0}}$

A systematic literature review for OTB showed that there is one reported analytical method to quantify OTB in rat plasma, where the percent recovery of OTB in rat plasma was $85.8 \%$ to 95.5\%. ${ }^{11}$ The reported method is a gradient method with a pharmacokinetic application. These findings motivated us to develop a validated isocratic LC-MS/MS method for estimating OTB with high recovery in human plasma. Our current developed proposed procedure is an isocratic method with very high reproducible recovery $(99.61 \pm 2.82 \%$, with $\mathrm{RSD}$ less than $2.17 \%$ ) for OTB quantification in human plasma with applications to evaluate OTB metabolic stability. For the evaluation of OTB metabolic stability, two important parameters were computed. These two parameters are intrinsic clearance and in vitro half-life $\left(t_{1 / 2}\right)$ that could be used for calculating in vivo $t_{1 / 2}$, hepatic clearance and bioavailability, which gives an idea about the investigated compound metabolism. If the tested 

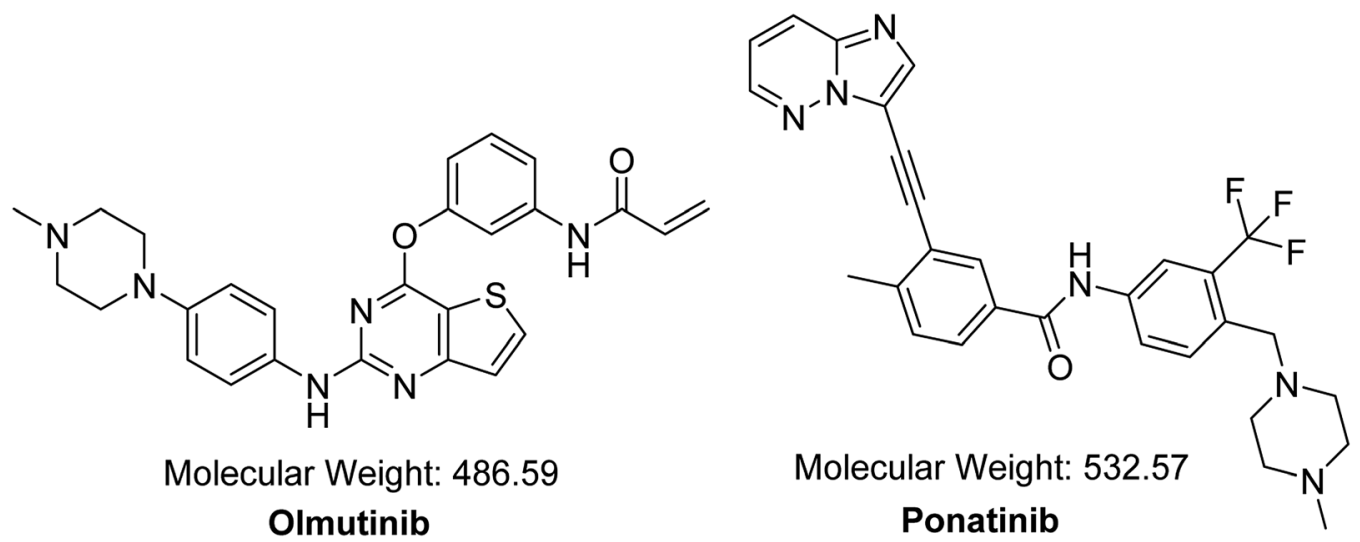

Fig. 1 Chemical structures of OTB and PNT (IS).

compound is rapidly metabolized in the human body, it can possess low bioavailability. ${ }^{12}$

\section{Experimental}

\subsection{Reagents and chemicals}

All chemicals and reagents are listed in Table 1. Human plasma was kindly supplied by King Khaled University Hospital (Riyadh, KSA) after permissions were obtained from human donors and stored at $-70{ }^{\circ} \mathrm{C}$ until usage. RLMs were prepared in-house using Sprague Dawley rats. ${ }^{13-16}$ Maintenance of the rats was done following the Animal Care Center guidelines at the College of Pharmacy at King Saud University (KSU) in Saudi Arabia. The animal experiment protocol was approved by the Institutional Review Board at KSU. The Ethics Review Committee at KSU approved the experimental design that was utilized for animal study.

\subsection{LC-MS/MS methodology}

All liquid chromatographic and mass spectrometric parameters were adjusted to achieve fast separation with high resolution. Table 2 shows all adjusted LC-MS/MS parameters. An isocratic elution mobile phase was used for the separation of OTB and IS.

PNT was chosen as IS in OTB analysis as the same method of extraction was applied successfully to OTB and PNT (OTB and PNT recoveries were $99.91 \pm 1.47 \%$ and $98.19 \pm 1.10 \%$ in human plasma, respectively) and the elution time of PNT was close to that of OTB with good resolution; thus, the method is fast with a short run time. Both PNT and OTB are TKIs and are not prescribed together for patients; thus, this method can be utilized for clinical applications such as pharmacokinetics or therapeutic drug monitoring (TDM) for patients under olmutinib treatment.

Detection was conducted on a QqQ mass detector connected to an electrospray ionization source (ESI) that was operated with a positive mode. Low-purity nitrogen $\left(11 \mathrm{~L} \mathrm{~min}^{-1}\right)$ was used as a drying gas in the ESI source and high-purity nitrogen (50 psi) was used as a collision gas inside the collision cell of the mass spectrometer. The ESI temperature and capillary voltage were adjusted to $350{ }^{\circ} \mathrm{C}$ and $4000 \mathrm{~V}$, respectively. The Mass Hunter software of Agilent was used to control the instruments and manage the data acquisition. Quantifying OTB was done using the multiple reaction monitoring (MRM) analyzer mode for the mass transitions (parent to product ion) from $487 \rightarrow 432$ and $487 \rightarrow 402$ for OTB and from $533 \rightarrow 433$ and $533 \rightarrow 260$ for PNT (IS) (Scheme 1). The fragmentor voltage (FV) was adjusted to 110 and $145 \mathrm{~V}$ with collision energies (CE) of 25 and 15 for OTB (FV of 135 and $140 \mathrm{~V}$ with CE of 20 and 25 for PNT). The MRM mode of the mass analyzer was used for OTB quantification to remove any interference from human plasma constituents and elevate the sensitivity of the developed LC-MS/MS methodology (Fig. 2).

\subsection{Standard solutions of OTB}

OTB (1.00 $\left.\mathrm{mg} \mathrm{mL}^{-1}\right)$ was solubilized in DMSO. Afterwards, the stock solution was diluted ten times with the mobile phase to

Table 1 List of chemicals and reagents

Name $^{a}$

Olmutinib (OTB) $(99.95 \%$ pure)

Ponatinib (PNT) (98.96\% pure)

Acetonitrile (ACN) and formic acid $(\mathrm{HCOOH})$

Water (HPLC grade)

RLMs

Human plasma

Sprague Dawley rats
Source

Med Chem. Express (USA)

LC Laboratories (USA)

Sigma-Aldrich (USA)

Milli-Q Plus instrument (USA)

Prepared in lab using Sprague Dawley rats ${ }^{13-16}$

King Khaled University Hospital (KSA)

The Animal Care Center at King Saud University (KSA)

${ }^{a}$ Reference powders are of analytical quality and all used solvents are HPLC quality. 
Table 2 Optimized parameters of the established LC-MS/MS methodology

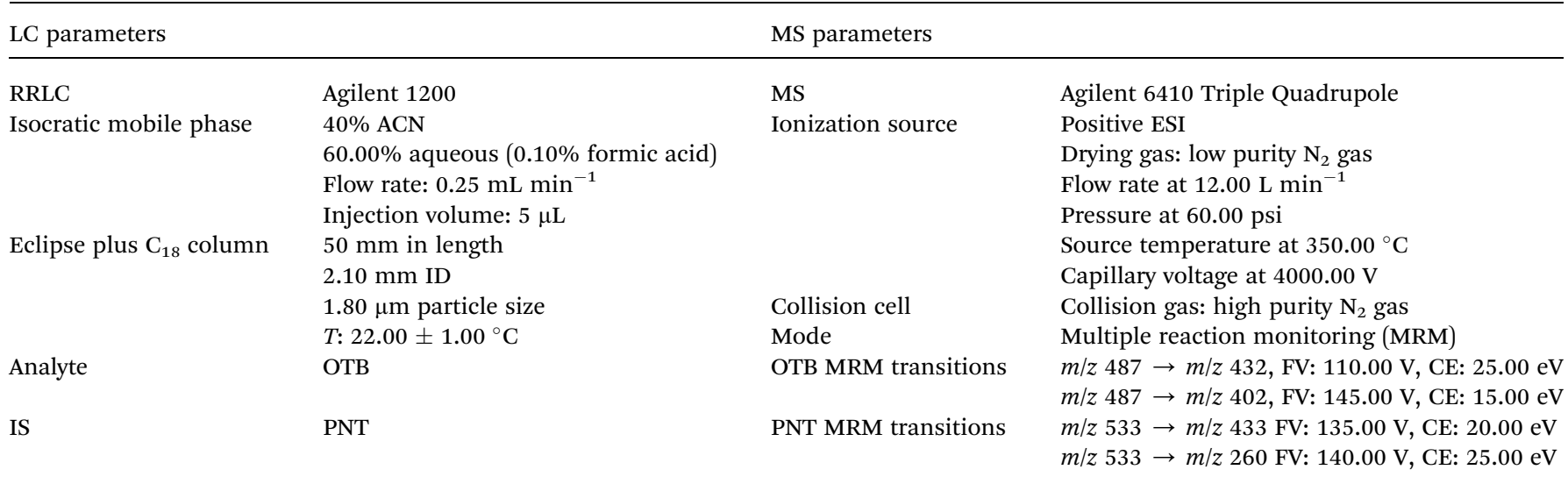

prepare working solution $1\left(100.00 \mu \mathrm{g} \mathrm{mL} \mathrm{m}^{-1}\right)$ that was further diluted ten times with the mobile phase to prepare working

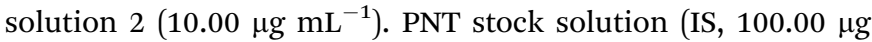
$\mathrm{mL}^{-1}$ ) was solubilized in DMSO. A working solution of PNT was made by diluting stock of PNT (IS) 50.00 times with the mobile phase to prepare working solution $3\left(2.00 \mu \mathrm{g} \mathrm{mL}{ }^{-1}\right)$.

\subsection{Preparation of OTB calibration standards}

OTB working solution $2\left(10.00 \mu \mathrm{g} \mathrm{mL}^{-1}\right)$ was mixed with certain volumes of human plasma matrix to generate fourteen calibration points: $5.00,10.00,15.00,20.00,30.00,40.00,50.00$, $80.00,100.00,150.00,200.00,300.00,400.00$ and $500.00 \mathrm{ng}$ $\mathrm{mL}^{-1}$. Three calibration standards $15.00 \mathrm{ng} \mathrm{mL}^{-1}, 150.00 \mathrm{ng}$ $\mathrm{mL}^{-1}$ and $400.00 \mathrm{ng} \mathrm{mL} \mathrm{m}^{-1}$ were selected as quality controls: low (LQC), medium (MQC) and high (HQC), respectively. Extraction was done using a protein precipitation technique by ACN. First, alkalinization of spiked plasma standards was conducted by adding $1 \mathrm{~mL}$ of $\mathrm{NaOH} /$ glycine buffer $(0.10 \mathrm{M}, \mathrm{pH} 9.5)$ followed by mixing for 30 seconds using a vortex. Second, two $\mathrm{mL}$ of ACN was added, followed by centrifugation at $14000 \mathrm{rpm}(12 \mathrm{~min}$ at

A)

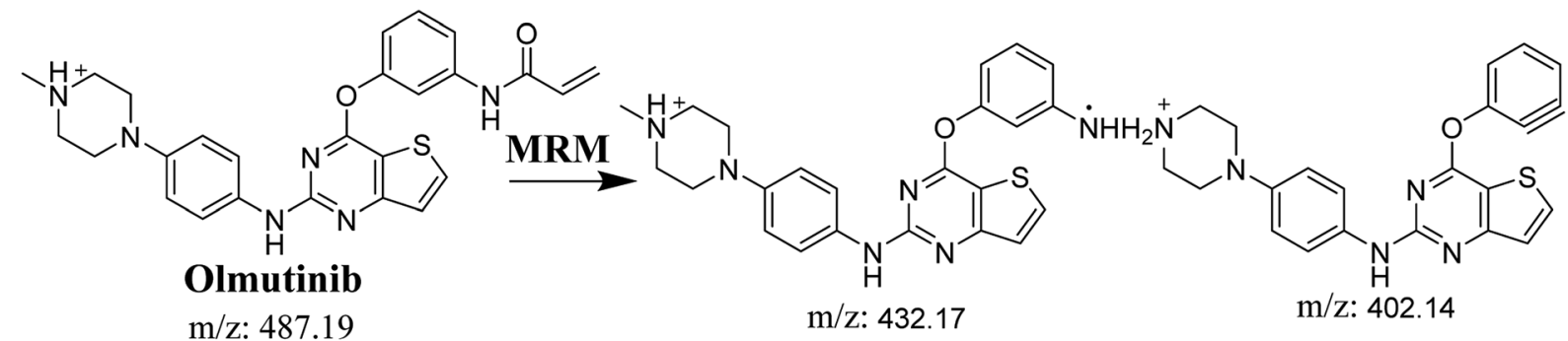

B)<smiles>C=C(C)NC(=O)c1ccc(C)c(C#Cc2cnc3cccnn23)c1</smiles>

$\mathrm{m} / \mathrm{z}: 533.23$<smiles>Cc1ccc(C(=O)Nc2ccc(F)c(C(F)(F)F)c2)cc1C#Cc1cnc2cccnn12</smiles>

$\mathrm{m} / \mathrm{z}: 433.13$<smiles>Cc1ccc(C#[O+])cc1C#Cc1cnc2cccnn12</smiles>

$\mathrm{m} / \mathrm{z}: 260.08$

Scheme 1 MRM ions of (A) OTB and (B) PNT (IS). 

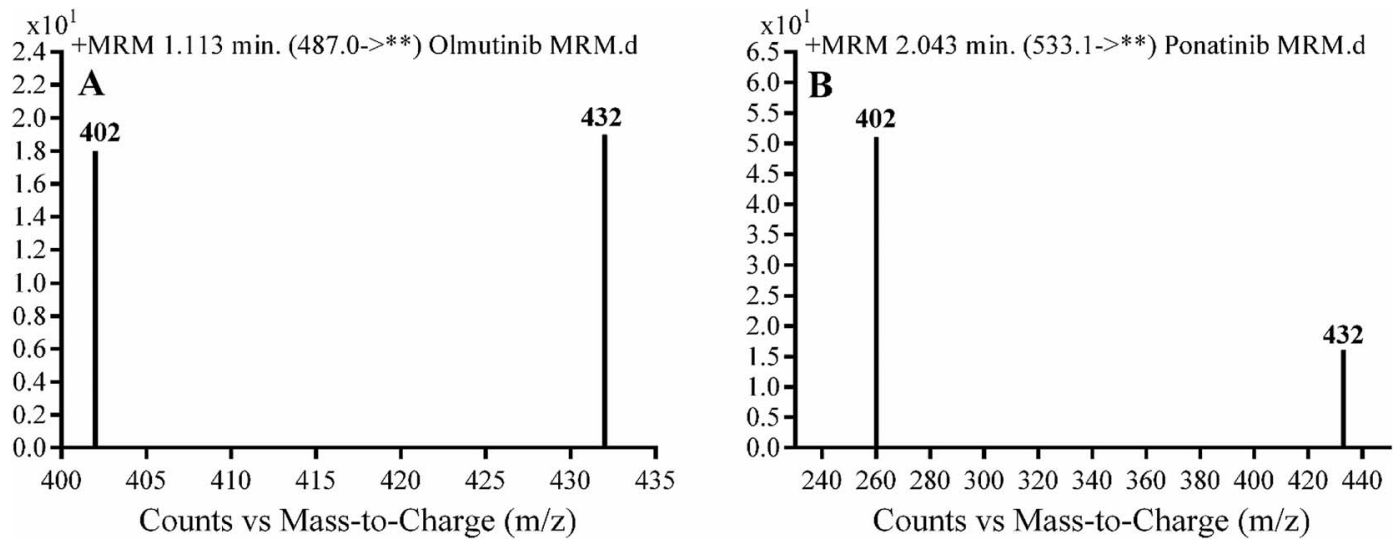

Fig. 2 MRM mass transition spectra of (A) olumtinib and (B) PNT (IS).

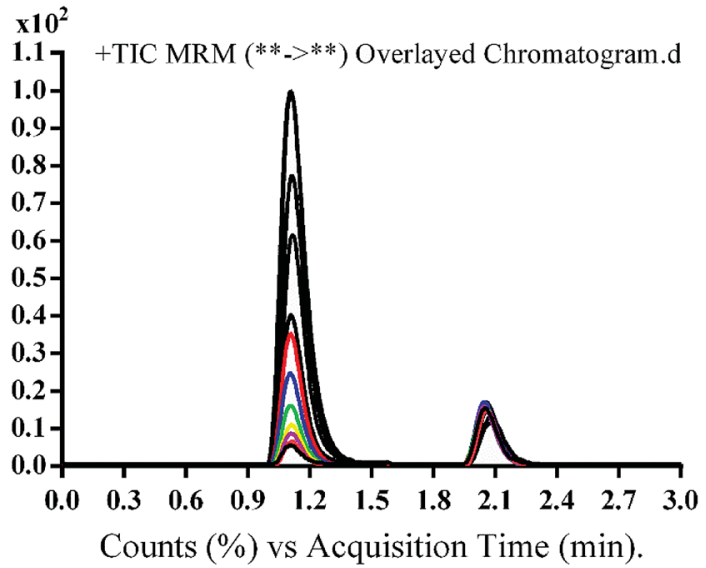

Fig. 3 MRM TIC of OTB calibration standards (5-500 $\mathrm{ng} \mathrm{mL} \mathrm{m}^{-1}$ ) and PNT (50 ng mL ${ }^{-1}$ ).

$4{ }^{\circ} \mathrm{C}$ ) to aid in protein precipitation. ${ }^{17}$ Supernatants were collected and then, filtration was done using a syringe filter $(0.22 \mu \mathrm{m}$ pore size). Fifty $\mu \mathrm{L}$ of PNT working solution 3 was added to $1 \mathrm{~mL}$ of the filtered samples and transferred to HPLC vials to be loaded into LC-MS/MS for analysis. Similarly, blank samples were prepared by utilizing the stated mobile phase in place of plasma to verify the absence of any interference from plasma components at RT of OTB and IS. A calibration curve was constructed for spiked human plasma by plotting the peak area ratio of OTB to PNT ( $y$ axis) against OTB standard nominal values ( $x$ axis). A linear regression equation was used to express the linearity of the established method. The slope, $r^{2}$ and intercept values were calculated.

\subsection{Method validation}

The validation parameters of the LC-MS/MS methodology that was developed to estimate OTB in human plasma were mentioned in detail earlier. ${ }^{17,18}$ They were calculated based on the assay recovery, linearity, sensitivity, specificity, reproducibility, limit of quantification (LOQ) and limit of detection (LOD). All these parameters were computed for OTB.

\subsection{Metabolic stability of OTB}

The metabolic stability of OTB was studied by measuring the decrease in OTB concentration when it was incubated with RLMs. One $\mu \mathrm{M}$ OTB was incubated with $1.00 \mathrm{mg} \mathrm{mL}{ }^{-1}$ microsomal proteins in triplicate. All incubations were kept for 10 minutes to reach $37{ }^{\circ} \mathrm{C}$ in a water bath. Initiation of the metabolic pathway was performed by adding $1 \mathrm{mM}$ NADPH in
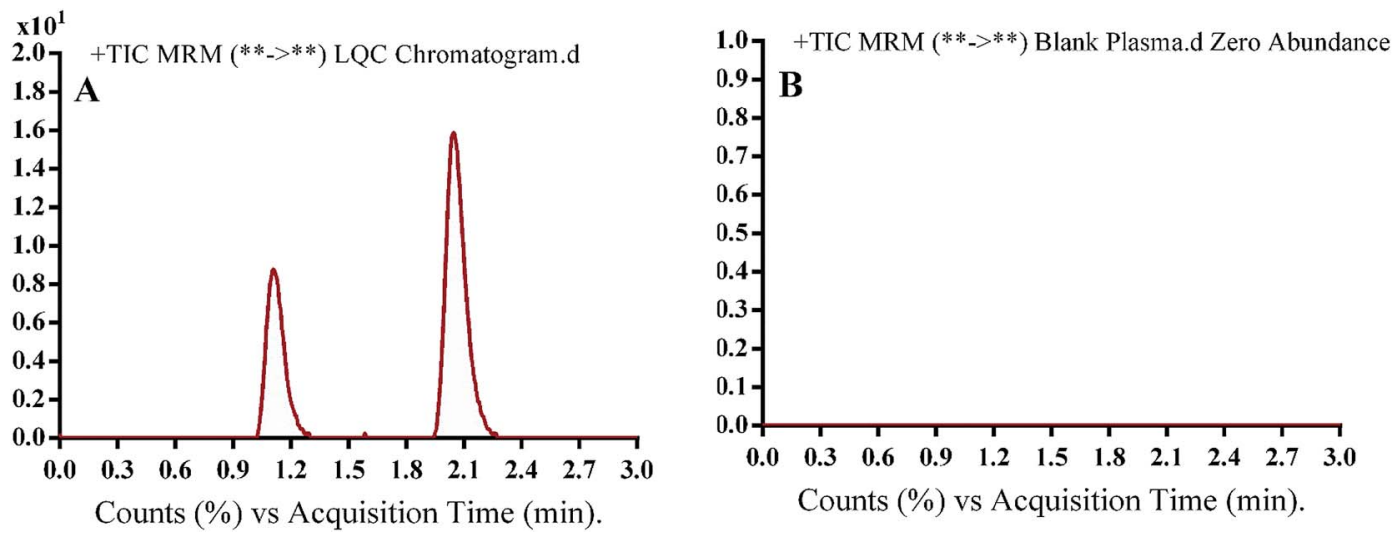

Fig. 4 MRM TIC of OTB lower quality control sample in human plasma (A) and blank human plasma (B) showing no matrix interference. 
Table 3 Data of OTB back-calculated concentrations of the calibration levels from the human plasma matrix

\begin{tabular}{lrrrr}
\hline $\begin{array}{l}\text { Nominal Concentrations } \\
\text { of OTB in } \mathrm{ng}^{-1}\end{array}$ & $\mathrm{Mean}^{a}$ & $\mathrm{SD}$ & $\mathrm{RSD}^{\circ}$ & Accuracy\% \\
\hline 5.00 & 5.10 & 0.14 & 2.73 & 101.98 \\
10.00 & 10.10 & 0.24 & 2.36 & 101.04 \\
15.00 & 15.27 & 0.45 & 2.93 & 101.83 \\
20.00 & 19.72 & 0.56 & 2.85 & 98.59 \\
30.00 & 28.76 & 0.61 & 2.13 & 95.88 \\
40.00 & 39.22 & 1.42 & 3.63 & 98.04 \\
50.00 & 49.59 & 0.85 & 1.71 & 99.19 \\
100.00 & 96.29 & 1.50 & 1.56 & 96.29 \\
150.00 & 147.91 & 3.33 & 2.25 & 98.61 \\
200.00 & 196.49 & 3.06 & 1.56 & 98.25 \\
300.00 & 305.67 & 3.96 & 1.29 & 101.89 \\
400.00 & 392.84 & 7.78 & 1.98 & 98.21 \\
500.00 & 494.15 & 4.90 & 0.99 & 98.83 \\
${ }^{a}$ Average of six replicates. & & & & \\
& & & &
\end{tabular}

phosphate buffer ( $\mathrm{pH}$ 7.4) that contained $3.30 \mathrm{mM} \mathrm{MgCl}_{2}$. Two $\mathrm{mL}$ ACN was added to terminate the metabolic pathway at certain time points: $0.00,2.50,5.00,7.50,10.00,15.00,20.00$, $40.00,60.00,90.00$ and $120.00 \mathrm{~min}$. The same method of extraction as mentioned above was utilized for OTB extraction. The metabolic stability curve for OTB was constructed.

\section{Results and discussions}

\subsection{HPLC-MS/MS methodology}

Optimizations of the chromatographic parameters including $\mathrm{pH}$, mobile phase constituents and RRLC column were conducted. The $\mathrm{pH}$ of the aqueous part $(0.1 \%$ formic acid) was adjusted to 3.2 as at $\mathrm{pH}$ values higher than this value, increase in elution time and peak tailing were observed. The ratio of mobile phase components (aqueous phase to ACN) was adjusted to $60 \%: 40 \%$ as more ACN led to overlapping of peaks with poor resolution and less ACN led to a delayed elution time. Various columns (Hilic columns) were checked but OTB and PNT were not retained. The best outcomes were obtained using a C18 column.

The chromatographic separation of OTB and PNT (IS) was attained in $3 \mathrm{~min}$. OTB and PNT chromatographic peaks resolved well in the absence of carryover in the blank samples: either the plasma matrix sample or plasma plus internal standard. Fig. 3 shows overlaid MRM total ion chromatograms (TIC) of OTB calibration standards.

\subsection{Method validation of the developed LC-MS/MS method}

3.2.1. Specificity. Fig. 4 shows excellent separation of OTB and PNT peaks and lack of any peak in the blank plasma matrix at their corresponding elution times, which ensured the developed methodology specificity. No carryover effect of OTB and PNT was seen in the MS chromatograms.

3.2.2. Sensitivity and linearity. The least square statistical method was utilized to compute calibration curve equations ( $y$ $=a x+b)$. A linear fit was verified by the coefficient of determination $\left(r^{2}\right)$, which was linear in the range from $5 \mathrm{ng} \mathrm{mL} \mathrm{m}^{-1}$ to $500 \mathrm{ng} \mathrm{mL}{ }^{-1}$. The recovery for OTB detected in the spiked human plasma samples was $99.61 \pm 2.82 \%$ with RSD less than $2.17 \%$.

The linearity range and correlation coefficient $\left(r^{2}\right)$ for the supposed methodology were $5-500 \mathrm{ng} \mathrm{mL} \mathrm{m}^{-1}$ and $\geq 0.9999$, respectively, in human plasma. The calibration curve regression equation of OTB in human plasma was $y=3.69 x-5.67$. LOD and LOQ were 1.12 and $3.39 \mathrm{ng} \mathrm{mL}{ }^{-1}$, respectively, in human plasma.

The RSD values of six repetitions for each concentration point in the calibration curve were lower than $3.63 \%$ in human plasma. Back calculation for the fourteen samples of OTB in plasma (calibration standards and QC levels) confirmed the performance of the developed methodology. The reproducibility and repeatability of the method were represented by the intraday and inter-day accuracy and precision, which were 1.17 to $2.75 \%$ and 97.86 to $101.48 \%$, respectively (Table 3 ). The mean percentage of OTB recoveries was $99.61 \pm 2.82 \%$ in the human plasma matrix.

3.2.3. Precision and accuracy. As mentioned in Table 4, the intra- and inter-day accuracy and precision values are accepted according to the US FDA guidelines. ${ }^{19}$

3.2.4. Matrix effects and extraction recovery. Table 5 depicts the recovery percentages of QCs for assessing the OTB concentration in human plasma. OTB and PNT recoveries were $99.91 \pm 1.47 \%$ and $98.19 \pm 1.10 \%$ in human plasma, respectively. The absence of the matrix effect on OTB or PNT (IS) was verified by analyzing six different batches of plasma, in which these batches were extracted and spiked with OTB LQC (15 ng $\mathrm{mL}^{-1}$ ) and PNT (50 ng $\mathrm{mL}^{-1}$ ). The above-mentioned batches were labeled as set 1 . Preparation of set 2 was conducted using a similar method, but the mobile phase was used instead of human plasma. Thus, the matrix effect was calculated utilizing the following equation:

Table 4 Precision and accuracy (intra-day and inter-day) of the developed methods

\begin{tabular}{|c|c|c|c|c|c|c|}
\hline Human plasma & \multicolumn{2}{|c|}{$\mathrm{LQC}, 15.00 \mathrm{ng} \mathrm{mL}^{-1}$} & \multicolumn{2}{|c|}{ MQC, $150.00 \mathrm{ng} \mathrm{mL}^{-1}$} & \multicolumn{2}{|c|}{$\mathrm{HQC}, 400.00 \mathrm{ng} \mathrm{mL} \mathrm{L}^{-1}$} \\
\hline SD & 0.42 & 0.37 & 2.18 & 2.47 & 5.57 & 4.59 \\
\hline Precision as \% RSD & 2.75 & 2.47 & 1.49 & 1.68 & 1.42 & 1.17 \\
\hline$\%$ accuracy & 101.48 & 100.47 & 97.86 & 98.17 & 98.21 & 98.38 \\
\hline
\end{tabular}

${ }^{a}$ Average of twelve replicates from day $1 .{ }^{b}$ Average of six replicates from three consecutive days. 
Matrix effect of OTB $=$ Mean peak area ratio $\frac{\text { Set } 1}{\text { Set } 2} \times 100$

Matrix effect of PNT $=$ Mean peak area ratio $\frac{\text { Set } 1}{\text { Set } 2} \times 100$

The studied human plasma that contains OTB and PNT showed values of $98.4 \pm 2.5 \%$ and $98.3 \pm 1.54 \%$, respectively. The internal standard normalized matrix effect (IS normalized MF) was computed from the following equation:

$$
\text { IS normalized MF }=\frac{\text { Matrix effect of OTB }}{\text { Matrix effect of PNT(IS) }}
$$

The IS normalized MF is 1.0 and it lies within the acceptable range. ${ }^{20}$ Accordingly, these results proved that the human plasma matrix has no noticeable effect on the ionization of OTB and PNT (IS).

3.2.5. Stability. QC samples were used for stability studies of OTB under many conditions. Table 6 shows the outcomes of such studies, where SD of the mean is lower than $5.10 \%$. Additionally, no observed change of OTB occurred throughout sample storage and handling under the inspected conditions. Also, the results showed the stability of plasma samples containing OTB under normal laboratory conditions with no remarkable loss of OTB concentration.

\subsection{Metabolic stability}

The metabolic stability of OTB in the RLM preparation was computed. The metabolic pathway was initiated using NADPH as a cofactor and terminated using ACN for enzyme deproteination. Stopping of the metabolic pathway occurred at various time points and extraction of OTB from different incubation points was performed following the same extraction procedure. The OTB concentration in the RLM matrix was computed by the displacement of the peak area ratios in the calibration curve regression equation. The experiment was repeated three times to confirm the results. The metabolic stability curve was drawn by plotting $\ln$ (percent of OTB remaining) on the $y$-axis against

Table 5 Recovery of OTB QC samples in human plasma matrix

\begin{tabular}{|c|c|c|c|}
\hline \multirow[b]{2}{*}{ Quality controls } & \multicolumn{3}{|l|}{ Human plasma matrix } \\
\hline & LQC, $15.00 \mathrm{ng} \mathrm{mL}^{-1}$ & $\begin{array}{l}\mathrm{MQC}, 150.00 \\
\mathrm{ng} \mathrm{mL}^{-1}\end{array}$ & $\begin{array}{l}\mathrm{HQC}, 400.00 \\
\mathrm{ng} \mathrm{mL}\end{array}$ \\
\hline $\operatorname{Mean}^{a}$ & 15.43 & 146.85 & 392.29 \\
\hline Recovery (\%) & 102.87 & 97.90 & 98.07 \\
\hline SD & 0.34 & 2.29 & 6.10 \\
\hline Precision (RSD\%) & 2.17 & 1.56 & 1.56 \\
\hline
\end{tabular}

IS conc. $(50$

\begin{tabular}{llll}
$\mathrm{ng} \mathrm{mL}$ & Mean & Recovery\% & SD \\
\hline PNT (IS) & 49.09 & 98.19 & 1.10
\end{tabular}

\footnotetext{
${ }^{a}$ Average of six replicates.
}

Table 6 OTB stability in human plasma matrix under various laboratory conditions

\begin{tabular}{|c|c|c|c|}
\hline Quality controls $^{a}$ & Mean \pm SD & $\begin{array}{l}\% \text { of } \\
\text { recovery }\end{array}$ & $\begin{array}{l}\text { Precision } \\
\text { (RSD\%) }\end{array}$ \\
\hline \multicolumn{4}{|c|}{ Room temp. for $\mathbf{8 h}$} \\
\hline 15.00 & $14.76 \pm 0.22$ & 98.40 & 1.48 \\
\hline 150.00 & $147.26 \pm 2.47$ & 98.17 & 1.68 \\
\hline 400.00 & $393.52 \pm 4.59$ & 98.38 & 1.17 \\
\hline \multicolumn{4}{|c|}{ Three freeze-thaw cycles } \\
\hline 15.00 & $14.84 \pm 0.42$ & 98.95 & 2.80 \\
\hline 150.00 & $146.70 \pm 5.00$ & 97.80 & 3.41 \\
\hline 400.00 & $399.19 \pm 6.25$ & 99.80 & 1.57 \\
\hline \multicolumn{4}{|c|}{$24 \mathrm{~h}$ storage at $4^{\circ} \mathrm{C}$} \\
\hline 15.00 & $14.74 \pm 0.50$ & 98.23 & 3.40 \\
\hline 150.00 & $145.07 \pm 3.79$ & 96.71 & 2.61 \\
\hline 400 & $390.14 \pm 5.50$ & 97.53 & 1.41 \\
\hline \multicolumn{4}{|c|}{30 days storage at $-20^{\circ} \mathrm{C}$} \\
\hline 15.00 & $14.33 \pm 0.36$ & 95.52 & 2.55 \\
\hline 150.00 & $144.15 \pm 4.03$ & 96.10 & 2.80 \\
\hline 400.00 & $388.49 \pm 4.92$ & 97.12 & 1.27 \\
\hline
\end{tabular}

time of incubation on the $x$-axis (Fig. 5). The linear part regression equation of the plotted curve was used for in vitro $t_{1 / 2}$ calculation ${ }^{21}$ using the following equations:

$$
\text { In vitro } t_{1 / 2}=\frac{\ln 2}{\text { Slope }}
$$

The slope was 0.0142 .

$$
\begin{gathered}
\text { In vitro } t_{1 / 2}=\frac{\ln 2}{0.0142} \\
\text { In vitro } t_{1 / 2}=48.8 \mathrm{~min} \text {. }
\end{gathered}
$$

The intrinsic clearance of OTB was calculated following the in vitro $t_{1 / 2}$ method $^{12}$ using the following equation:

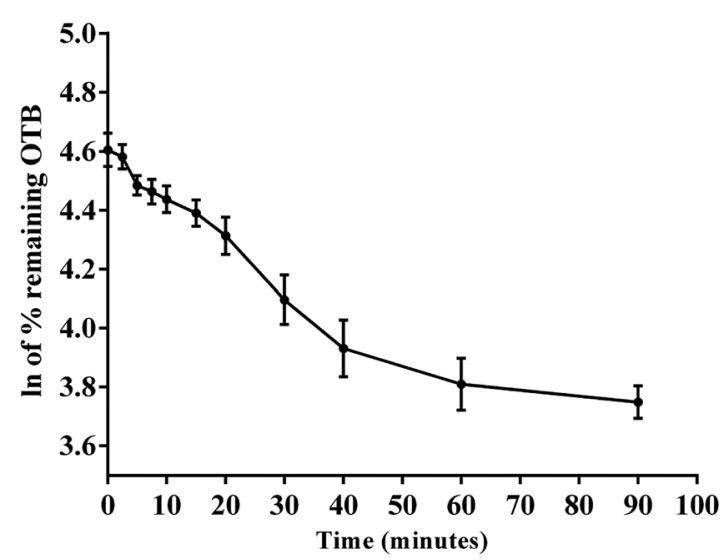

Fig. 5 OTB metabolic stability curve. 
Table 7 Metabolic stability parameters of OTB incubation with RLMs for specific time intervals

OTB metabolic stability parameters

\begin{tabular}{|c|c|c|c|c|}
\hline Time (min.) & $\begin{array}{l}\text { Conc. (ng } \\
\mathrm{mL}^{-1} \text { ) }\end{array}$ & $X^{a}$ & Parameter & Value \\
\hline 0 & 473.00 & 4.61 & Regression equation $^{b}$ & $y=-0.0142 x+4.5894$ \\
\hline 5.00 & 429.24 & 4.48 & $R^{2 c}$ & 0.9836 \\
\hline 7.50 & 463.01 & 4.46 & & \\
\hline 10.00 & 460.71 & 4.44 & Slope & 0.0142 \\
\hline 40.00 & 380.55 & 4.10 & & \\
\hline 60.00 & 401.23 & 3.93 & $\mathrm{CL}_{\mathrm{int}}^{e}$ & $2.71 \mathrm{~mL} \mathrm{~min}{ }^{-1} \mathrm{~kg}^{-1}$ \\
\hline 90.00 & 418.84 & 3.81 & & \\
\hline 120.00 & 444.95 & 3.75 & & \\
\hline
\end{tabular}

$$
\begin{aligned}
\mathrm{CL}_{\text {int }, \text { app }}= & \frac{0.693}{\text { in vitro } t_{1 / 2}} \times \frac{\mathrm{mL} \text { incubation }}{\mathrm{mg} \text { microsomes }} \times \frac{45 \mathrm{mg} \text { microsome }}{\mathrm{g} \text { liver }} \\
& \times \frac{20 \mathrm{~g} \text { liver }}{\mathrm{kg} \text { per body weight }}
\end{aligned}
$$$$
\mathrm{CL}_{\text {int }, \mathrm{app}}=\frac{0.693}{48.8} \times \frac{1}{1} \times \frac{45}{13.1} \times \frac{20}{0.36}
$$$$
\mathrm{CL}_{\text {int,app }}=2.71 \mathrm{~mL} \mathrm{~min}^{-1} \mathrm{~kg}^{-1}
$$

From the previous results, the metabolic assessment of OTB was characterized by a lower value of $\mathrm{CL}_{\text {int }}\left(2.71 \mathrm{~mL} \mathrm{~min}^{-1} \mathrm{~kg}^{-1}\right)$ and a longer in vitro $t_{1 / 2}$ value $(48.8 \mathrm{~min})$, which resulted in slower clearance of OTB from the blood by the liver and probable high in vivo bioavailability (Table 7).

\section{Conclusions}

A reliable and precise LC-MS/MS methodology was established for assaying the newly approved drug OTB in plasma. The established method is very sensitive $\left(\mathrm{LOD}=1.12 \mathrm{ng} \mathrm{mL}{ }^{-1}\right)$, ecofriendly (using small volumes of organic solvents), rapid (run time $=3$ min. $)$ and accurate $(R \%=98.4 \pm 2.5 \%)$. The adopted LC-MS/MS methodology was utilized for OTB metabolic stability assessment in RLM matrix using two terms: in vitro $t_{1 / 2}(2.71$ $\mathrm{min}$ ) and intrinsic clearance $\left(48.8 \mathrm{~mL} \mathrm{~min}^{-1} \mathrm{~kg}^{-1}\right)$. From these two values, we concluded that OTB can be classified among lowextraction ratio drugs and hence can be slowly eliminated from the human body.

\section{Authors' contribution}

MWA, AAK and HWD participated in putting the design of the research in addition to guiding the practical work. HWD, ASA and MWA performed the optimization and method validation experiments and manuscript writing. All the authors participated in revising and approving the final draft of the manuscript.

\section{Conflicts of interest}

The authors declare that they have no competing interests.

\section{List of abbreviations}

$\begin{array}{ll}\text { CE } & \text { Collision energy } \\ \text { EGFR } & \text { Epidermal growth factor receptor } \\ \text { FV } & \text { Fragmentor voltage } \\ \text { HQC } & \text { High quality control } \\ \text { IS } & \text { Internal standard } \\ \text { IS normalized } & \text { Internal standard normalized matrix effect } \\ \text { MF } & \\ \text { LC-MS/MS } & \text { Liquid chromatography tandem mass } \\ & \text { spectrometry } \\ \text { LOD } & \text { Limit of detection } \\ \text { LQC } & \text { Lower quality control } \\ \text { LOQ } & \text { Limit of quantification } \\ \text { MQC } & \text { Medium quality control } \\ \text { NSCLC } & \text { Non-small cell lung cancer } \\ \text { OTB } & \text { Olmutinib } \\ \text { PNT } & \text { Ponatinib } \\ \text { QC } & \text { Quality control } \\ \text { TKI } & \text { Tyrosine kinase inhibitor }\end{array}$

\section{Acknowledgements}

The authors would like to extend their sincere appreciation to the Deanship of Scientific Research at the King Saud University for funding this work through the Research Group Project No. RGP-322. 


\section{References}

1 A. Jemal, R. Siegel, E. Ward, Y. Hao, J. Xu, T. Murray, et al., Cancer statistics, Ca-Cancer J. Clin., 2008, 58(2), 71-96.

2 M. Barinaga, From bench top to bedside, Science, 1997, 278(5340), 1036-1039.

3 J. Ferlay, I. Soerjomataram, R. Dikshit, S. Eser, C. Mathers, M. Rebelo, et al., Cancer incidence and mortality worldwide: sources, methods and major patterns in GLOBOCAN 2012, Int. J. Cancer, 2015, 136(5), E359-E86.

4 D. S. Ettinger, W. Akerley, G. Bepler, M. G. Blum, A. Chang, R. T. Cheney, et al., Non-small cell lung cancer, J. Natl. Compr. Cancer Network, 2010, 8(7), 740-801.

5 J. E. Larsen, T. Cascone, D. E. Gerber, J. V. Heymach and J. D. Minna, Targeted therapies for lung cancer: clinical experience and novel agents, Cancer J., 2011, 17(6), 512.

6 C. Gridelli, A. Rossi, D. P. Carbone, J. Guarize, N. Karachaliou, T. Mok, et al., Non-small-cell lung cancer, Nat. Rev. Dis. Primers, 2015, 1, 15009.

7 S. Peters, S. Zimmermann and A. A. Adjei, Oral epidermal growth factor receptor tyrosine kinase inhibitors for the treatment of non-small cell lung cancer: comparative pharmacokinetics and drug-drug interactions, Cancer Treat. Rev., 2014, 40(8), 917-926.

8 C.-S. Tan, D. Gilligan and S. Pacey, Treatment approaches for EGFR-inhibitor-resistant patients with non-small-cell lung cancer, Lancet Oncol., 2015, 16(9), e447-e459.

9 B.-C. Liao, C.-C. Lin and J. C.-H. Yang, Second and thirdgeneration epidermal growth factor receptor tyrosine kinase inhibitors in advanced nonsmall cell lung cancer, Curr. Opin. Oncol., 2015, 27(2), 94-101.

10 E. S. Kim, Olmutinib: First Global Approval, Drugs, 2016, 76(11), 1153-1157.

11 S.-s. Bao, J. Wen, T.-h Liu, B.-w Zhang, C.-c Wang and G.-x Hu, A UHPLC-MS/MS method for the quantitation of olmutinib in rat plasma, Acta Chromatogr., 2018, 1-4.

12 P. Baranczewski, A. Stanczak, K. Sundberg, R. Svensson, A. Wallin, J. Jansson, et al., Introduction to in vitro estimation of metabolic stability and drug interactions of new chemical entities in drug discovery and development, Pharmacol. Rep., 2006, 58(4), 453-472.

13 R. von Jagow, H. Kampffmeyer and M. Kiese, The preparation of microsomes, Naunyn-Schmiedebergs Arch. Exp. Pathol. Pharmakol., 1965, 251(1), 73-87.

14 A. A. Kadi, M. Attwa and H. W. Darwish, LC-ESI-MS/MS reveals the formation of reactive intermediates in brigatinib metabolism: elucidation of bioactivation pathways, RSC Adv., 2018, 8(3), 1182-1190.

15 S. M. Amer, A. A. Kadi, H. W. Darwish and M. W. Attwa, Identification and characterization of in vitro phase I and reactive metabolites of masitinib using a LC-MS/MS method: bioactivation pathway elucidation, RSC Adv., 2017, 7, 4479-4491.

16 A. A. Kadi, H. W. Darwish, M. W. Attwa and S. M. Amer, Detection and characterization of ponatinib reactive metabolites by liquid chromatography tandem mass spectrometry and elucidation of bioactivation pathways, RSC Adv., 2016, 6(76), 72575-72585.

17 A. A. Kadi, H. W. Darwish, M. W. Attwa and S. M. Amer, Validated LC-MS/MS Method for the Quantification of Ponatinib in Plasma: Application to Metabolic Stability, PLoS One, 2016, 11(10), e0164967.

18 S. M. Amer, A. A. Kadi, H. W. Darwish and M. W. Attwa, Liquid chromatography tandem mass spectrometry method for the quantification of vandetanib in human plasma and rat liver microsomes matrices: metabolic stability investigation, Chem. Cent. J., 2017, 11(1), 45.

19 FDA, Guidance for industry bioanalytical method validation, 2001.

20 N. Kadian, K. S. R. Raju, M. Rashid, M. Y. Malik, I. Taneja and M. Wahajuddin, Comparative assessment of bioanalytical method validation guidelines for pharmaceutical industry, J. Pharm. Biomed. Anal., 2016, 126, 83-97.

21 G. Caldwell and Z. Yan, Optimization in drug discovery: in vitro methods, Springer Science \& Business Media, 2014. 